\title{
New insights into the genome of Rhodococcus ruber strain Chol-4
}

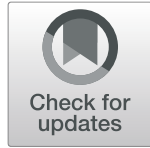

Govinda Guevara ${ }^{*}$, Maria Castillo Lopez ${ }^{1}$, Sergio Alonso ${ }^{2}$, Julián Perera ${ }^{1}$ and Juana María Navarro-Llorens ${ }^{1 *}$ (D)

\begin{abstract}
Background: Rhodococcus ruber strain Chol-4, a strain isolated from a sewage sludge sample, is able to grow in minimal medium supplemented with several compounds, showing a broad catabolic capacity. We have previously determined its genome sequence but a more comprehensive study of their metabolic capacities was necessary to fully unravel its potential for biotechnological applications.

Results: In this work, the genome of R. ruber strain Chol-4 has been re-sequenced, revised, annotated and compared to other bacterial genomes in order to investigate the metabolic capabilities of this microorganism. The analysis of the data suggests that $R$. ruber Chol-4 contains several putative metabolic clusters of biotechnological interest, particularly those involved on steroid and aromatic compounds catabolism.

To demonstrate some of its putative metabolic abilities, $R$. ruber has been cultured in minimal media containing compounds belonging to several of the predicted metabolic pathways. Moreover, mutants were built to test the naphtalen and protocatechuate predicted catabolic gene clusters.

Conclusions: The genomic analysis and experimental data presented in this work confirm the metabolic potential of $R$. ruber strain Chol-4. This strain is an interesting model bacterium due to its biodegradation capabilities. The results obtained in this work will facilitate the application of this strain as a biotechnological tool.
\end{abstract}

Keywords: Rhodococcus ruber, Catabolism, Biodegradation, Genome analysis

\section{Background}

Rhodococci belong to the taxon of nocardioform actinomycetes. These aerobic Gram-positive bacteria are found in diverse environmental niches and are world-widely distributed being abundant in soil, water and marine environments [1]. They differ from other Actinomycetes and are called the Mycolata because their distinctive cell envelope contains large branched chain lipids known as mycolic acids [2]. The genome size of these non-sporulating mycolic-acid-containing bacteria varied for different strains from $4.3 \mathrm{Mb}$ (e.g. R. rhodnii strain LMG5362, [3]) to $10.0 \mathrm{Mb}$ (e.g. R. wratislaviensis, GCA_000583735.1).

Rhodococci are known for displaying a wide metabolic versatility and for their ability to transform a varied range of pollutants such as aliphatic and aromatic hydrocarbons, oxygenated and halogenated compounds,

\footnotetext{
*Correspondence: fguevara@ucm.es; joana@bio.ucm.es

${ }^{1}$ Departamento de Bioquímica y Biología Molecular, Facultad de Ciencias

Biológicas, Universidad Complutense de Madrid, Madrid, Spain

Full list of author information is available at the end of the article
}

nitroaromatics, heterocyclic compounds, nitriles, and various pesticides [4]. The analysis of their genomes has revealed a multiplicity of genes, a high genetic redundancy of metabolic pathways, and a complex regulatory network [5]. Moreover, some Rhodococcus strains harbor circular and linear plasmids that contain genes encoding additional catabolic enzymes [6-8]. Even the extracellular polysaccharides of the outer membrane of rhodococci contribute to the catabolism of aromatic compounds [9]. This versatile metabolic capacity and also their environmental persistence and tolerance to stress conditions make Rhodococcus strains good candidates for biotechnological processes such as bioremediation, biotransformations or biocatalysis $[4,10,11]$. On the other hand, Rhodococcus strains are able to synthesize compounds of industrial interest including biosurfactants [12] and steroid precursors [13]. For all these reasons, the characterization of different Rhodococcus metabolic capabilities is necessary to fully exploit their biotechnological potential.

(c) The Author(s). 2019 Open Access This article is distributed under the terms of the Creative Commons Attribution 4.0 International License (http://creativecommons.org/licenses/by/4.0/), which permits unrestricted use, distribution, and reproduction in any medium, provided you give appropriate credit to the original author(s) and the source, provide a link to the Creative Commons license, and indicate if changes were made. The Creative Commons Public Domain Dedication waiver (http://creativecommons.org/publicdomain/zero/1.0/) applies to the data made available in this article, unless otherwise stated. 
Rhodococcus ruber strain Chol-4, isolated from a sewage sludge sample, is classified as a Gram-positive bacteria belonging to the actinobacteria taxon with a high guanine-cytosine content [14]. This strain is able to grow in minimal medium supplemented with several aromatic compounds, showing a broad catabolic capacity. We have recently published the draft genome sequence of this bacterium [15]. The analysis of the genomic sequence of different bacterial species, i.e. the presence of specific genes or gene families, allows inferring their particular metabolic capabilities. In this work we present novel and more comprehensive results, both computational and experimental, that support the versatile metabolic potential of $R$. ruber strain Chol-4.

\section{Methods}

\section{Bacterial strains and culture conditions}

The bacterial strains and plasmids used in this work are listed in Additional file 1.

E. coli $D H 5 \alpha$ was purchased to Thermo Fisher Scientific. E. coli GM48 was obtained from the E. coli Genetic Resources Collection (CGSC5127 number) and E. coli S17.1 was obtained from the ATCC Bacteriology Collection (ATCC 47055 number). Rhodococcus ruber strain Chol-4, a strain isolated from a sewage sludge sample [14], and their derived mutants have been obtained in our laboratory.

Escherichia coli cells were grown at $37^{\circ} \mathrm{C}$ in Luria Bertani (LB) [16]. Rhodococcus ruber and its derived mutant strains were routinely grown in LB or minimal medium (Medium 457 of the DSMZ, Braunschweig, Germany) containing the desired carbon and energy source under aerobic conditions at $30^{\circ} \mathrm{C}$ in a rotary shaker $(250 \mathrm{rpm})$ for 1-3 days. Where appropriate, antibiotic were added at the following concentrations: ampicillin $(100 \mu \mathrm{g} / \mathrm{mL})$, nalidixic acid $(15 \mu \mathrm{g} / \mathrm{mL})$ or kanamycin $(25-50 \mu \mathrm{g} / \mathrm{mL}$ for E. coli or $200 \mu \mathrm{g} / \mathrm{mL}$ for Rhodococcus). For the growth experiments, a LB pre-grown culture was washed two times with minimal medium prior to inoculation of $10 \mathrm{~mL}$ of fresh minimal medium (initial $\mathrm{DO}_{600 \mathrm{~nm}}=0.05$ ) supplemented with an organic compound as only source of energy and carbon. Volatile compounds such as indane, tetralin, isopropanol, 1,3-butanediol, 2,3-butanediol, xylene, benzene, ethylbenzene, toluene, phenylacetic acid or styrene were provided supplied in gas phase via saturated atmosphere (Additional file 2). Aromatic compounds were used at $1 \mathrm{mg} / \mathrm{mL}$ of naphthalene in powder, $10 \mathrm{mM}$ sodium benzoate, $2 \mathrm{mM}$ phenol, $5 \mathrm{mM}$ L-tryptophan, $4 \mathrm{mM}$ vanillic acid, $4 \mathrm{mM}$ gentisate, $5 \mathrm{mM}$ homogentisate, $2 \mathrm{mM}$ catechol, $2.2 \mathrm{mM}$ cholic acid, 2 $\mathrm{mM}$ DHEA and $10 \mathrm{mM}$ protocathecuate, $15 \mathrm{mM}$ biphenyl, $20 \mathrm{mM}$ phthalate, $5 \mathrm{mM} 2$-aminobenzoate, from 2 to $4 \mathrm{mM}$ salicylic acid, $0.5 \mathrm{mM}$ hydroxyquinol or 2 mM L-tyrosine. DHEA (dehydroepiandrosterone) and cholic acid were previously dissolved in $16.5 \mathrm{mM}$ methyl- $\beta$-cyclodextrin to form inclusion complexes following a modification of a previously reported method [17] and prepared as described [18]. Although it is not necessary to add methyl- $\beta$-cyclodextrin to dissolve cholic acid at the concentrations employed in our experiments, we have used them in the cholic acid growth experiments to homogenize the experimental conditions for compounds with similar structures (e.g. steroids). Biological replicas (2 to 5 replicates) were performed for all growth experiments.

Competent and electrocompetent cells of $E$. coli were prepared and transformed as previously described [16]. Selection of transformed cells was carried out in LB agar plates supplemented with appropriate antibiotics.

\section{DNA manipulation and sequencing}

Chromosomal DNA extraction from $R$. ruber strain Chol-4 was performed using the Cetyl Trimethyl Ammonium Bromide procedure [19]. Briefly, bacterial cells were collected from a LB plate, resuspended in $400 \mu \mathrm{L}$ Tris-EDTA buffer (10 mM Tris/HCl, pH 8, 1 mM EDTA) and incubated at $80^{\circ} \mathrm{C}$ for $20 \mathrm{~min}$. Then, $50 \mu \mathrm{L}$ of lysozyme $(100 \mathrm{mg} / \mathrm{mL})$ was added and incubated at $37^{\circ} \mathrm{C}$ for $12 \mathrm{~h}$. Afterwards, $70 \mu \mathrm{L}$ of $10 \%$ SDS and $5 \mu \mathrm{L}$ of proteinase $\mathrm{K}(10 \mathrm{mg} / \mathrm{mL})$ were added and the sample was incubated for $10 \mathrm{~min}$ at $65^{\circ} \mathrm{C}$. Proteins were precipitated with $100 \mu \mathrm{l}$ of $5 \mathrm{M} \mathrm{NaOH}$ and $100 \mu \mathrm{l}$ CTAB $(0.1 \mathrm{~g} / \mathrm{ml}$ resuspended in $0.7 \mathrm{M} \mathrm{NaOH}$ ) for $10 \mathrm{~min}$ at $65^{\circ} \mathrm{C}$. DNA was purified by extraction with chloroform-isoamyl alcohol (24:1) and phenol-chloroform-isoamyl alcohol (25:24:1) and precipitated with $0.6 \mathrm{vol}$ of isopropanol at room temperature for $30 \mathrm{~min}$. After centrifugation, DNA was washed with $70 \%$ ethanol and resuspended in sterile water.

Manipulation of genomic DNA was carried out according to standard protocols [16], and the extracted DNA was purified three times to achieve highest purity and quality for subsequent sequencing of the complete genome.

Two independent NGS experiments were combined to generate this new version of the $R$. ruber Chol-4 de novo genomic assembly. One was previously performed using Roche 454 technology [15]. A new one based on massively parallel pyrosequencing of the genomic DNA was done by Biejing Genomics Institute, BGI - Hong Kong Laboratory (Hong Kong, China), using Illumina HiSeq 2000 platform. A 500 bp short-insert library was constructed and a $91 \mathrm{PE}$ sequencing was used as strategy. Before data delivery, Incoming Quality Control and three levels of Quality Control processes (e.g. GC content and depth correlative analysis) were performed by BGI. 
The program SPAdes v3.1.0 [20] was employed to assemble the reads. This assembler accepts different formats for the input sequences (Fasta, FastaQ, single-end, pair-end, etc.), thus allowing the combination of sequences generated by different sequencing platforms. Four large sequences previously generated in our lab by conventional cloning and Sanger sequencing (JQ083440.1, JQ083439.1, EU878550.1 and FJ842098.2) were entered as trusted contigs (--trusted-contigs flag), Illumina reads as paired-reads and Roche reads as unpaired. To reduce the number of mismatches and short indels, mismatch corrector was run after the initial assembly by specifying the flag --careful in the SPAdes command. The quality assessment of the genome assembly was done using QUAST [21]. Manual curation of the assembly was subsequently carried out in order to reduce the number of contigs, based on their length, the $\mathrm{G}+\mathrm{C}$ content and sequence similarity of the generated contigs with other known species.

\section{Mutagenesis of $R$. ruber strain Chol-4}

Unmarked gene deletions were carried out as described previously in $R$. erythropolis SQ1 involving conjugative transfer of a mutagenic plasmid carrying the $s a c B$ selection system [22]. Specific sets of primers were designed from the up and downstream sequences of each cluster (ketoadipate and naphtalen pathway). Polymerase chain reaction (PCR) amplicons were obtained from isolated $R$. ruber strain Chol-4 genomic DNA. Primers and conditions employed in the experiments are summarized in Additional file 3. To facilitate cloning, the primer sequences included restriction sites: the ketoadipate cluster contained EcoRI-XbaI for the up fragment, and $X b a I-H i n d I I I$ for the down fragment; the naphtalen cluster contained XhoI-HindIII and XbaI-HindIII for the up and down fragment, respectively.

PCR amplicons (up and down fragments) were first cloned separately into pGEM-T-Easy vectors and then combined in order to get an EcoRI-HindIII and XhoI-HindIII fragments containing a truncated cluster. Transformation into E.coli GM48 was necessary in order to avoid dam methylation of the XbaI site. The EcoRI-Hin$d \mathrm{III}$ and XhoI-HindIII inserts, containing the fused up and down fragments, were transferred to pK18mobsacB plasmid [23] to construct the mutagenic plasmid $\mathrm{pK} 18(\mathrm{U}+\mathrm{D})$ used for the partial deletion of the corresponding cluster from $R$. ruber strain Chol-4 chromosome.

Every mutagenic plasmid was introduced into $E$. coli S17.1 and mobilized to $R$. ruber strain Chol-4 by conjugation as previously described [19]. $R$. ruber transconjugants that had integrated the plasmid by homologous recombination were selected on LB plates supplemented with nalidixic acid. The cluster fragment deletion was achieved as a result of a second spontaneous homologous recombination process within the genome of $R$. ruber strain Chol-4. Colony PCR detection was performed to confirm the deletion in the nar and pca clusters in the mutant $R$. ruber strains.

\section{Genome analysis and annotation}

Homology searches were performed using the BLAST server of the NCBI (http://blast.ncbi.nlm.nih.gov/Blast. cgi). The annotation of the genome was carried out using the GenBank tool PGAP and the on-line service RAST (http://rast.nmpdr.org/). The complete genome sequence has been deposited at GenBank under accession number NZ_ANGC00000000.2. The program Circos was used to visualize genomic data [24].

\section{Pulsed field gel electrophoresis (PFGE)}

PFGE was performed from $10 \mathrm{~mL}$ of a cell culture grown at $\mathrm{OD}_{600 \mathrm{~nm}}$ of 0.8-1.0. Cells were collected by centrifugation and suspended in $0.5 \mathrm{~mL}$ of cell suspension solution $(10 \mathrm{mM}$ Tris- $\mathrm{HCl} \mathrm{pH} 7.2,20 \mathrm{mM} \mathrm{NaCl}, 100 \mathrm{mM}$ EDTA). Plugs containing the cells were prepared with $1.5 \%$ agarose, placed in lysis buffer $(1 \mathrm{mg} / \mathrm{mL}$ lysozyme, $10 \mathrm{mM}$ Tris- $\mathrm{HCl} \mathrm{pH} 7.2,50 \mathrm{mM} \mathrm{NaCl}, 100 \mathrm{mM}$ EDTA, $0.2 \%$ DOC, $0.5 \%$ N-laurylsarcosine sodium salt, $0.06 \mathrm{~g} / \mathrm{L}$ RNase) and incubated for $1 \mathrm{~h}$ at $37^{\circ} \mathrm{C}$ with soft shaking. Lysis was followed by two washes in $20 \mathrm{mM}$ Tris- $\mathrm{HCl}$ $\mathrm{pH} 8$ and $50 \mathrm{mM}$ EDTA. The plugs were placed in $3 \mathrm{~mL}$ proteinase solution $(1 \mathrm{mg} / \mathrm{mL}$ proteinase $\mathrm{K}, 100 \mathrm{mM}$ EDTA pH 8.0, 1\% N-lauryilsarcosine sodium salt, $0.2 \%$ DOC) and incubated with gently shaken at $42{ }^{\circ} \mathrm{C}$ for 18 $\mathrm{h}$. After removing the proteinase solution, $9 \mathrm{~mL}$ TE containing $40 \mu \mathrm{g} / \mathrm{mL}$ PMSF were added and kept at $50^{\circ} \mathrm{C}$ for one hour, repeating the whole process two times. After washing twice for $15 \mathrm{~min}$ in $20 \mathrm{mM}$ Tris- $\mathrm{HCl} \mathrm{pH}$ 8, $50 \mathrm{mM}$ EDTA the DNA in plugs was resolved by PFGE on a contour-clamped homogeneous electric field II Mapper system (Bio-Rad Laboratories) in $0.5 \times$ Tris-borate-EDTA and the following running conditions: $6 \mathrm{~V} / \mathrm{cm}$ for $18-24 \mathrm{~h}$ at $13{ }^{\circ} \mathrm{C}$, with a 50 -s switch time. Gels were stained in Gel Red solution $(5 \mathrm{~min})$ and photographed under UV light.

\section{Phytosterol consumption followed by mass spectrometry- high performance liquid chromatography (MS-HPLC)}

$R$. ruber was grown at $30^{\circ} \mathrm{C}$ with $200 \mathrm{rpm}$ shaking, in 25 $\mathrm{mL}$ of minimal medium (M457 of the DSMZ, Braunschweig, Germany) supplemented with a mixture of industrial phytosterols in powder (around $0.7 \mathrm{mg} / \mathrm{mL}$ ), kindly given by Gadea S.A. Two $\mathrm{mL}$ aliquots were collected at different times and $1 \mathrm{mg}$ of pregnenolone was added as internal control of the extraction. The steroid fraction was extracted twice with $2 \mathrm{~mL}$ of chloroform. HPLC and MS determination was carried out in the 
Chromatography Service of the Biological Research Center ("Centro de Investigaciones Biológicas" CIB-CSIC). The relative peak area was calculated as the ratio between the HPLC peak area obtained for each phytosterol (brassicasterol, campesterol, stigmasterol and $\beta$-sitosterol) and the peak area of pregnenolone used as internal control. The experiment was done twice.

\section{Results}

\section{General genome features}

$R$. ruber strain Chol-4 genome was sequenced using two different Next Generation Sequencing (NGS) technologies. First, a genomic library was generated and sequenced in a Roche 454 GS FLX instrument. After quality filtering and adapter clipping, this library rendered 242,042 reads with an average length of $400 \mathrm{bp}$ [15]. A second library was independently generated and processed by pair-end sequencing in an Illumina HiSeq 2000 instrument (see methods). This library generated 2,782,965 pair end reads of $90 \mathrm{bp}$ with an average fragment size of $500 \mathrm{bp}$ between pairs. Single-reads from the 454 library and pair-end reads from the Illumina library were combined with four larger sequences (6.3 to 11.7 $\mathrm{Kb})$ that we previously obtained by standard cloning and Sanger sequencing (GenBank accession numbers JQ083440.1, JQ083439.1, EU878550.1 and FJ842098.2). All the sequences were assembled using SPAdes de novo assembler v3.1.0 [20]. The initial assembly generated 129 sequence scaffolds between $128 \mathrm{bp}$ and $1,025,475 \mathrm{bp}$ covering $5.63 \mathrm{Mb}$, with N50 of 438,623 bp and L50 of 4). These scaffolds were named successively according to their length, being Scaffold_001 the longest and Scaffold_129 the shortest (Additional file 4). This nomenclature was maintained in the final version of the assembly uploaded to GenBank (NZ_ANGC00000000.2). The vast majority $(n=126)$ of these scaffolds were composed of a single sequence contig with no internal gaps. Hence, for all practical purposes, 'scaffold' and 'contig' denominations would be interchangeable in this work. To streamline the final assembly, twenty scaffolds shorter than $500 \mathrm{bp}$, and covering less than $3.5 \mathrm{~kb}$ in total, were discarded. Of the remaining 109 scaffolds, 65 (161.2 kb) exhibited a $\mathrm{G}+\mathrm{C}$ content below $55 \%$, and sequence similarity to plasmid vectors and genomes from unrelated species. These scaffolds presumably originated from cross-contamination of the NGS experiments, where several libraries were sequenced in parallel in the same flow cell, and therefore they were removed from the final assembly. The remaining 44 scaffolds of the final assembly exhibited a high $\mathrm{G}+\mathrm{C}$ content (70.7\%) typical of Rhodococci, and very high sequence similarity to other Rhodococcus genomes. These 44 scaffolds covered $5.46 \mathrm{Mb}$ with N50 of 438,623 bp, L50 of 4, and an average read depth above 100X. These sequences are available from the NCBI GenBank database under the accession numbers NZ_ANGC00000NNN.1, where $\mathrm{NNN}$ indicates the scaffold number. We provide a more detailed report of the assembly in Additional file 5.

Figure 1a shows the DNA sequence similarity between $R$. ruber Chol-4 genome and $R$. pyridinivorans SB3094 (GenBank: NC_023150.1), one of its closest relatives. The figure provides an approximation of how the $R$. ruber contigs might be arranged along its genome assuming a high degree of synteny with $R$. pyridinovorans. No evidence of circular plasmids in the genome of $R$. ruber Chol-4 was found by pulsed-field gel electrophoresis. However, some genetic elements present in other Rhodococcus plasmids were found interspersed along the Chol-4 genome (Fig. 1b).

\section{Annotation of Rhodococcus ruber strain Chol-4}

Genome annotation using RAST server [25] identified 5049 coding sequences and 59 RNAs. 53 out of the 59 RNAS are tRNAs representing 43 different anticodons are encoded in the $R$. ruber genome (Additional file 6). There were at least 7 tRNAs in multicopy: tRNA $^{\text {Met }}$ (ATG) is present in 4 copies, tRNA ${ }^{\text {Gly }}$ (GGC) in 3 copies and tRNA ${ }^{\text {Val }}$ (GTC), tRNA ${ }^{\text {Glu }}$ (GAG), tRNA ${ }^{\text {Ala }}$ (GCC), tRNA $^{\text {Asp }}$ (GAC) and tRNA ${ }^{\text {Leu }}$ (CTC) in 2 copies. The codon usage correlated with the high $\mathrm{G}+\mathrm{C}$ content of this strain as $G+C$ codons are predominant in this organism (Additional file 6). Codons that have a $\mathrm{T}$ at the third position lacked a cognate tRNA in $R$. ruber with the single exception of Arg (CGT).

The number of tRNAs was similar to others Rhodococcus strains that display a median value of 53 tRNAs although there are exceptions such as $R$. rhodnii ASM72037v1 that contains 69 tRNAs (EMBL: NZ_JOAA00000000.1). The genomic assembly revealed a single $r r n$ operon located in the NZ_ANGC02000002.1 contig containing the genes for $16 \mathrm{~S}, 23 \mathrm{~S}$ and $5 \mathrm{~S}$ rRNA.

The 4861 protein-coding detected ORFs covered nearly $91 \%$ of the genome. Among the coding sequences, the analysis revealed at least 129 genes related to the metabolism of aromatic compounds: 15 of them involved in peripheral degradation pathways (quinate, benzoate and $p$-hydroxibenzoate degradation), 15 genes related to the aromatic amine catabolism and 6 genes associated with the gentisate degradation pathway. A small number of genes were involved in the resistance to antibiotics (resistance to vancomycin, fluoroquinolones, $\beta$-lactamase), while a relatively large number of genes were related to the resistance to toxic compounds, such as mercury and arsenic.

\section{Mobile elements}

Within the genome of the strain Chol-4 we found a few mobile elements (Additional file 7), some of them 

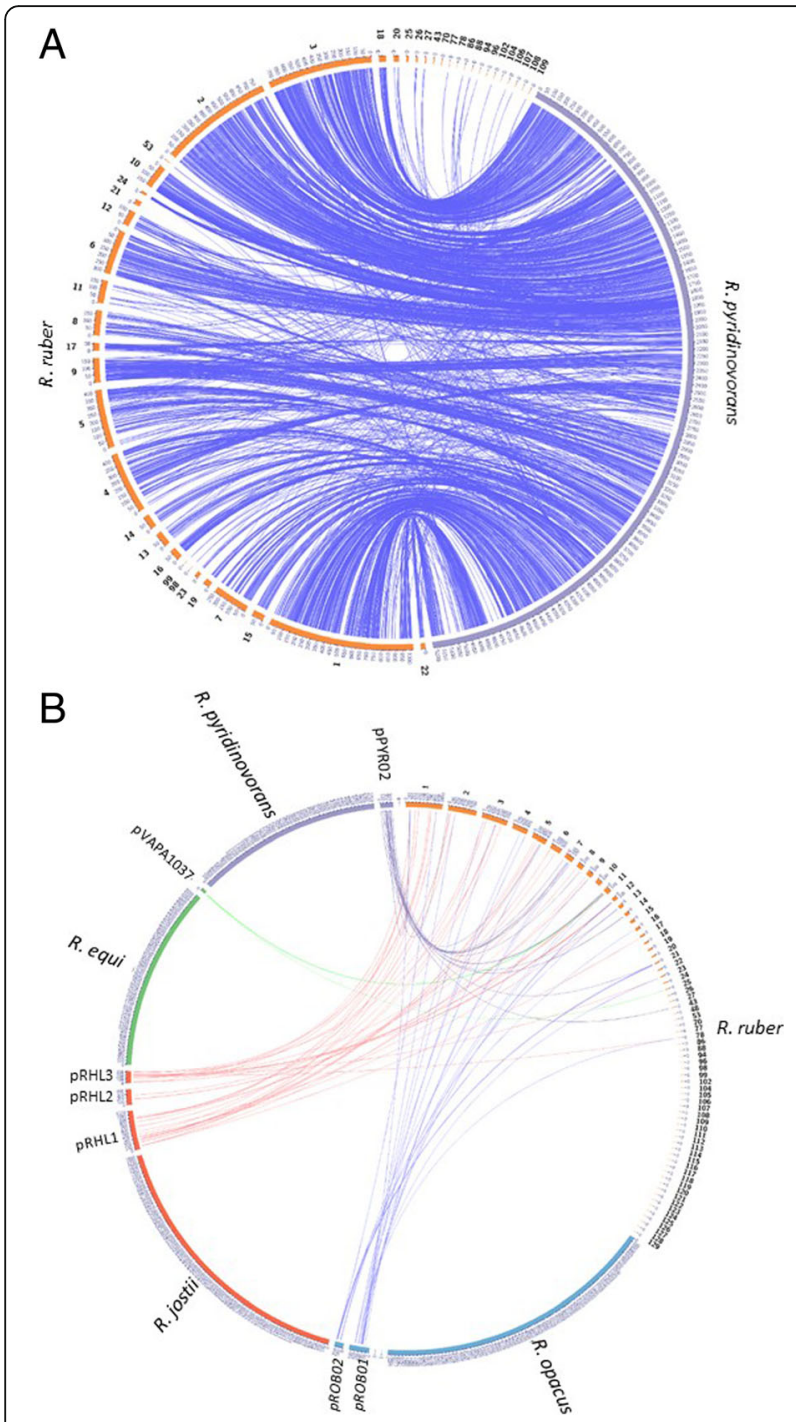

Fig. 1 Sequence homology of the 44 scaffolds of R. ruber strain Chol-4 genome assembly (in orange) with the genome of closely related Rhodococcus bacteria. In a the comparison with the chromosome of its closest relative, $R$. pyridinivorans (in purple). R. ruber strain Chol-4 scaffolds are ordered and oriented according to their probable genomic location assuming a high level of synteny between these two microorganisms. The internal blue edges indicate regions of sequence homology above $70 \%$ with a minimum length of $0.5 \mathrm{~kb}$. Scaffold order and orientation were computed to minimize de number of cross-overs among edges. In b comparison with the chromosomes and extrachromosomic elements of R. pyridinivorans (purple), R. equi (green), R.jostii (red) and R. opacus (blue). This color code is also use for the internal edges indicating regions of sequence homology above $70 \%$ with a minimum length of $0.5 \mathrm{~kb}$. For simplicity, only the homology with extrachromosomal elements is shown. R. ruber strain Chol-4 genome scaffolds are ordered according to their length. Many of the sequences found in the large plasmids pPYR02 (R. pyridinovorans), pVAPA1037 (R. equi), pRHL1-3 (R. jostii) and pROB01-02 (R. opacus), are also present in the genome of $R$. ruber strain Chol-4. In both $A$ and $B$, the small font numbers outside the scaffolds indicate their internal coordinate, in $\mathrm{kb}$. The large font numbers indicate the chromosome, plasmid or scaffold names as they appear in the original GenBank entries remaining as pseudogenes. Surprisingly, $25 \%$ of these mobile elements were concentrated in a $120 \mathrm{~kb}$ region of NZ_ANGC020000011.1 contig.

$R$. ruber Chol-4 genome had two copies of IS1164 from the IS256 transposase family (the prototype of a major family of bacterial insertion sequence elements) in NZ_ANGC02000007.1 contig. This element has also been found in other Rhodococcus strains [5]. In the same contig there were two genes (D092_RS18300 and D092_RS17945) coding for an identical protein keeping a $90-92 \%$ base identity with elements of Rhodococcus pyridinivorans SB3094 plasmid (CP006997.1) and with elements of the pNSL1 plasmid (KJ605395.1) from Rhodococcus $s p$. NS1. Both genes share $84 \%$ identity with a transposase of Mycobacterium sp.

Other two IS elements, described for some Rhodocococcus, were absent in this genome: the IS2112 element belonging to the IS110 family found in $R$. rhodochrous NCIMB 13064 and related to genome rearrangements [26] and the IS1166 element from the IS256 family, found in R. erythropolis IGTS8 [27].

Apart from those derived of mobile elements, strain Chol-4 contains many different recombinases with different putative roles (Additional file 8).

\section{Other genetic elements}

Some actinobacteria such as Mycobacterium tuberculosis contain from 1 to 3 clustered regularly interspaced short palindromic repeats (CRISPR) elements (CRISPR database, https://crispr.i2bc.paris-saclay.fr/ crispr/) [28]. However, R. ruber apparently is a strain devoid of detectable CRISPRs systems, similarly to other Rhodococcus strains. On the other hand, we found a gene cluster related to specialized protein degradation systems that includes a $20 \mathrm{~S}$ proteasome activity (subunits $\alpha$ and $\beta$ ), an ATPase (that use ATP to unfold proteins and translocate them into the proteasome) and a system of tagging proteins for degradation with Pup prokaryotic ubiquitin-like protein. Conjugation with Pup serves as a signal for degradation by the mycobacterial proteasome (Fig. 2) [29, 30]. Most of the restriction modification systems detected in this genome are classified as type I or IV (Additional file 9).

\section{Aromatic compounds specific gene clusters}

The $R$. ruber Chol- 4 genome annotation revealed the presence of a rich set of gene cluster that may code for several aromatic compounds catabolic pathways, reflecting a high potential for degrading this kind of compounds. The catabolism of aromatic compounds proposed for $R$. ruber is outlined in Fig. 3 showing the peripheral, central and basic pathways. 


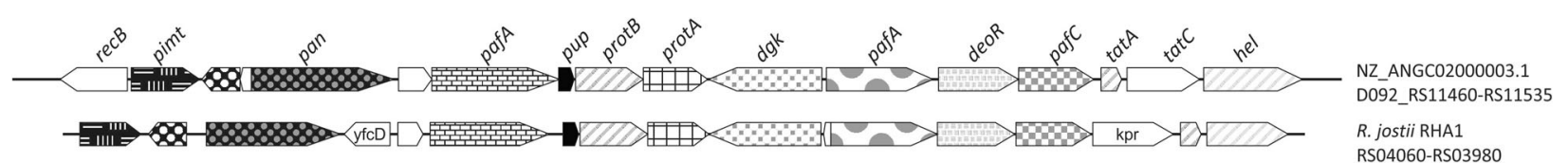

Fig. 2 Pup proteasome in R. ruber. Abbreviations: recB: RecB family exonuclease; pimt: protein-L-isoaspartate methyltransferase; pan: bacterial proteasome-activating AAA-ATPase; pafA: proteasome accessory factor, Pup ligase PafA' paralog, possible component of postulated heterodimer PafA-PafA'; pup: prokaryotic ubiquitin-like protein Pup; protA and protB: proteasome subunit a and $\beta$ bacterial; dgk: diacylglycerol kinase; deoR: putative DeoR-family transcriptional regulator; pafC: DNA-binding protein; tatA and tatC: twin-arginine translocation proteins; hel: DEAD/DEAH box helicase; yfcD: nudix hydrolase YfCD; kpr: 2-dehydropantoate 2-reductase. All R. jostii RHA1 genes have the prefix "RHA1_" not included in the figure

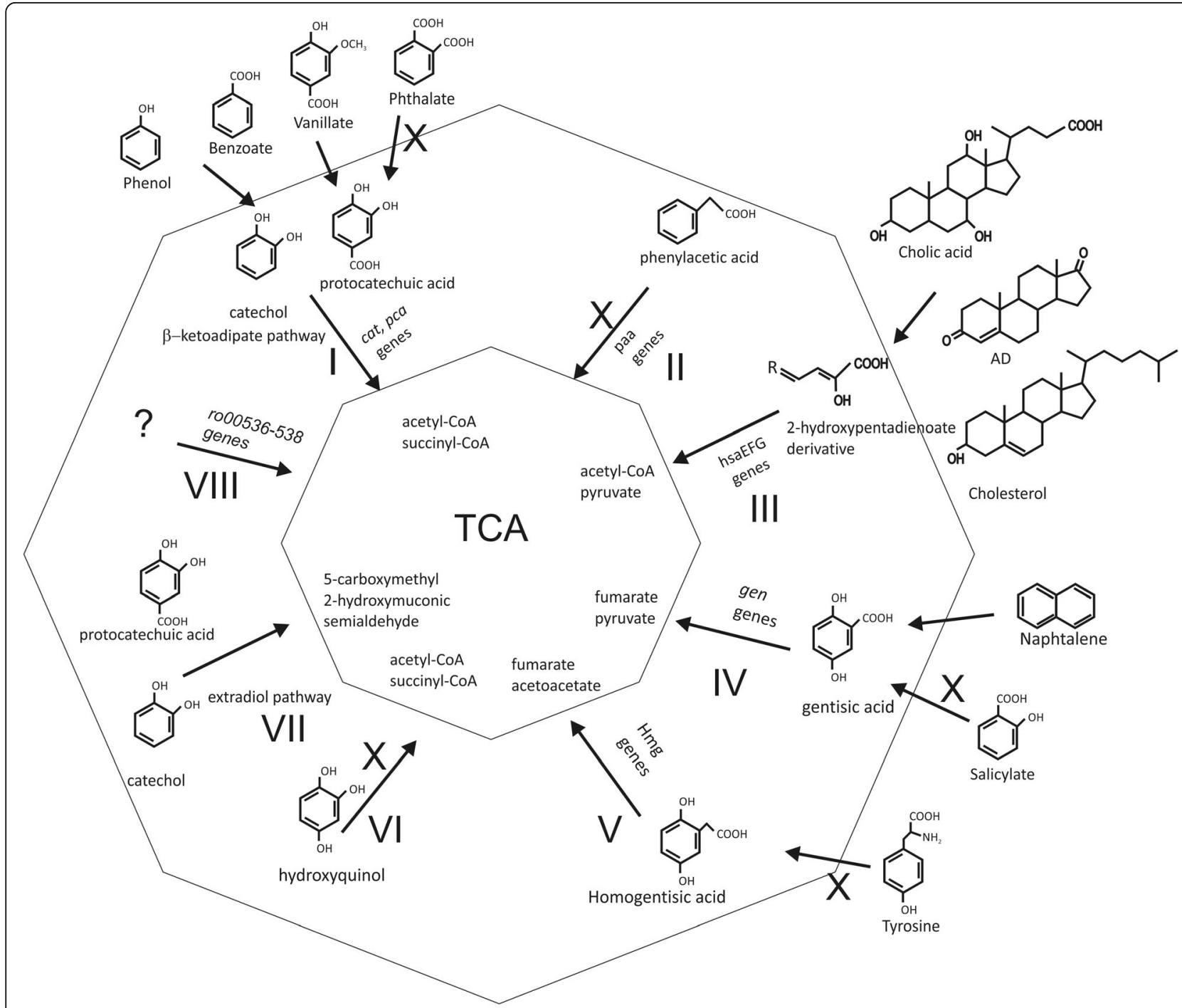

Fig. 3 Aromatic compounds metabolism. Scheme of the aromatic compounds catabolic pathways: I) $\beta$-ketoadipate pathway, II) phenylacetate pathway, III) 2-hydroxypentadienoate pathway, IV) gentisate pathway, V) homogentisate pathway), VI) hydroxyquinol pathway, VII) homoprotocatechuate pathway, and VIII) a pathway found in R. jostii RHA1 comprising a hydroxylase, an extradiol dioxygenase, and a hydrolase. Peripheral pathways are depicted outside the external ring. The " $X$ " indicates the inability of $R$. ruber to grow in the presence of these compounds as single source of carbon and energy 


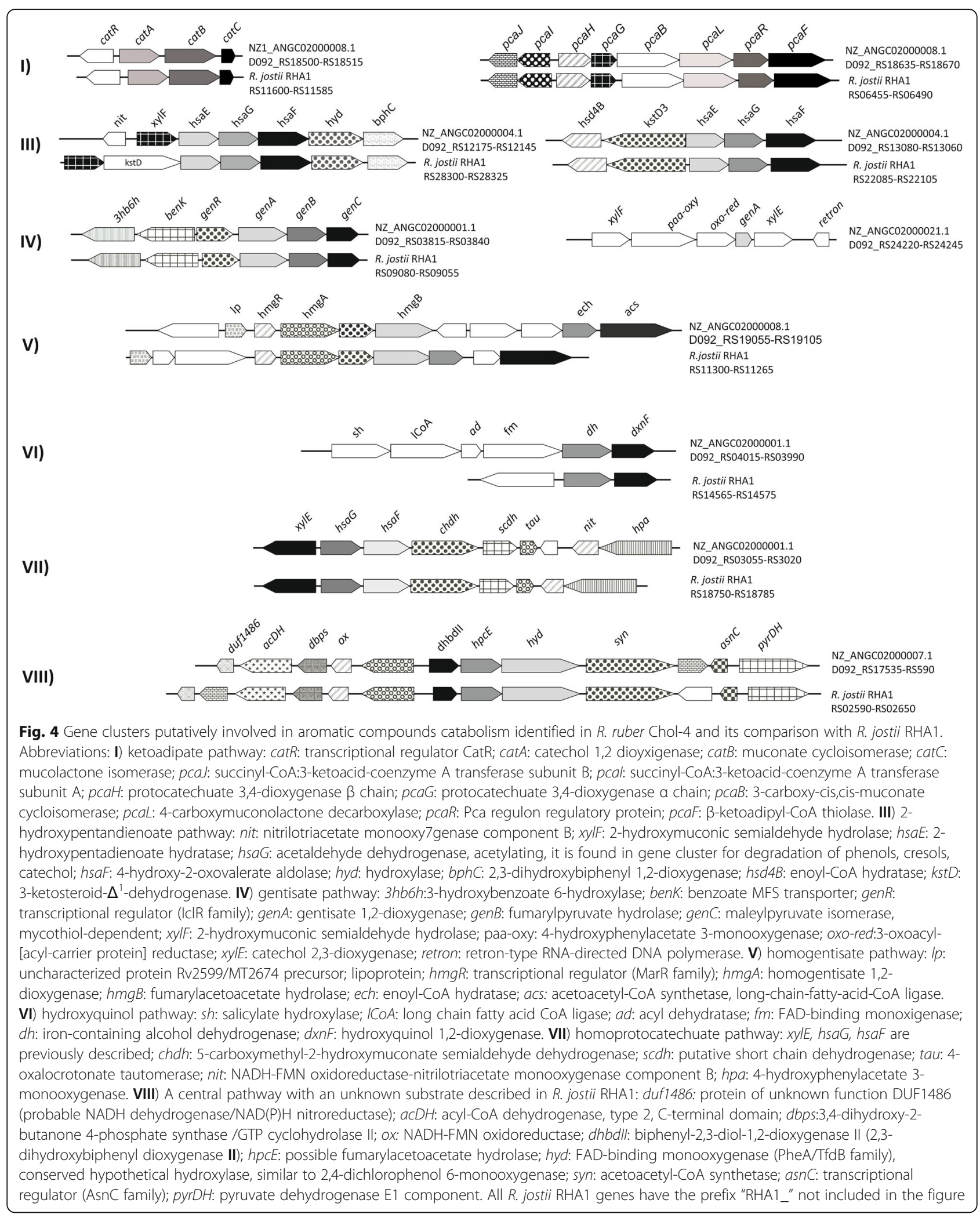




\section{Central pathways}

There are eight central aromatic pathways chromosomally encoded in $R$. jostii RHA1 and $R$. opacus B4 [31, 32] and 7 of them are found in $R$. ruber: 1) the $\beta$-ketoadipate or ortho-cleavage pathway encoded by the $p c a$ and cat genes and responsible for the conversion of catechol and protocatechuate into acetyl-CoA and succinyl-CoA by intradiol cleavage of the catecholic intermediate (Fig. 4 I); 2) the phenylacetate pathway encoded by the paa genes [33], that takes part in the catabolism of a variety of compounds, including homophthalate, tropate and phenylalkanoates. This pathway was not found in $R$. ruber); 3) the 2-hydroxypentadienoate pathway that transforms 2-hydroxypentadienoates into acetyl-CoA and pyruvate through the successive action of a hydratase, an aldolase and a dehydrogenase (Fig. 4 III) [34]; 4) the gentisate pathway encoded by the gen $A B C$ gene cluster that converts gentisate to pyruvate and fumarate (Fig. 4 IV) [35]; 5) the homogentisate pathway encoded by the $h m g A B C$ genes that involves the extradiol cleavage of homogentisate, followed by a $\mathrm{C}-\mathrm{C}$ bond hydrolysis to finally yield fumarate and acetoacetate (Fig. 4 V) [36]; 6) the hydroxyquinol pathway responsible of an intradiol-type cleavage of 4-hydroxysalicylate/hydroxyquinol leading to aceyl-CoA and succinyl-CoA (Fig. 4 VI) [37]; 7) the homoprotocatechuate pathway encoded by the $h p c$ genes and involved in the extradiol-type cleavage of homoprotocatechuate (Fig. 4 VII); 8) lastly, a putative metabolic pathway for an unknown substrate that would be made up of a hydroxylase, an extradiol dioxygenase and a hydrolase (Fig. 4 VIII) [31, 32].

\section{Peripheral pathways}

Some of the above aromatic compounds are intermediates in the degradation pathways of other more complex compounds that are also growing substrates of $R$. ruber Chol-4 and whose catabolic pathways meet those previously presented as central pathways. The Chol-4 genes encoding the putative necessary enzymatic activities of these peripheral pathways are described below.

Gene clusters ben, cat and pca (Fig. 4i and Fig. 5a) could be involved in the benzoate degradation. Isopropylbenzene degradation genes were found in a gene cluster in NZ_ANGC02000001.1 contig, and also in a different gene cluster in NZ_ANGC02000021.1 contig (Fig. 5b). In Fig. 5c some of the steroid catabolic gene clusters contained in the $R$. ruber genome are depicted. Transport systems related to steroid molecules are also of interest and therefore mammalian cell entry (MCE) systems that have been associated with steroid transport $[38,39]$ were searched through the genomic data. Figure 6 collects all the MCE systems found in the R. ruber genome.
A putative gene cluster for vanillate degradation was found in R. ruber genome (GenBank: Y11521, Fig. 5d). Probably involved in naphtalene catabolism, a nar gene cluster containing two regulatory genes, narR1 belonging to the GntR family and NarR2 of the NtrC family of enhancer-binding proteins has been also found in the $R$. ruber Chol-4 genome (Fig. 5e). NZ_ANGC02000009.1 contig (Fig. 5f) contained a putative anaerobic degradation gene cluster for an acetophenone carboxylase activity. There was also another cluster containing a phenylalanine dehydrogenase putatively involved in amino acid catabolism (Fig. 5g).

Other gene clusters that occur in related bacteria were not found in the $R$. ruber Chol-4 genome, such as the bph cluster for biphenyl catabolism, [40] and the pad cluster for phthalate catabolism [41].

\section{Growth in different organic compounds}

In order to determine the growth capabilities of Rhodococcus ruber strain Chol-4, we analyzed its ability to use several compounds as sole energy and carbon source (Table 1).

The growth curves of $R$. ruber with some of the metabolizable compounds (sodium benzoate, cholic acid, gentisate, naphthalene or DHEA as sole carbon source) are shown in Fig. 7.

$R$. ruber was isolated by its capacity to degrade steroid compounds like cholesterol. In this work, its growth capabilities using other steroids of interest such as plant sterols was investigated. Cells were grown on minimal medium supplemented with a mix of phytosterols (plant sterols that included brassicasterol, campesterol, stigmasterol and $\beta$-sitosterol) as only source of energy and carbon. The sterol consumption was followed by HPLC. The results proved that sterol concentration was reduced to $5 \%$ of the initial value (Fig. 8).

\section{Mutant construction}

Unmarked gene deletions were carried out in the $p c a$ and nar gene clusters of $R$. ruber strain Chol-4 to verify the involvement of these genes in the growth of protocatechuate and naphthalene, respectively. A scheme of the introduced deletions is depicted in Fig. 9 A. Mutants were confirmed by PCR and growth experiments proved that nar $R$. ruber mutants lost the ability to grow on naphthalene; similarly, pca $R$. ruber mutants were not able to grow on protocatechuate (Fig. 9 B).

On the other hand, the growth of the nar and pca $R$. ruber mutants was also checked with different carbon sources (Table 2). The nar mutant could grow in all alternative substrates tested. The pca mutant, however, lost the capability to grow in vanillate. 


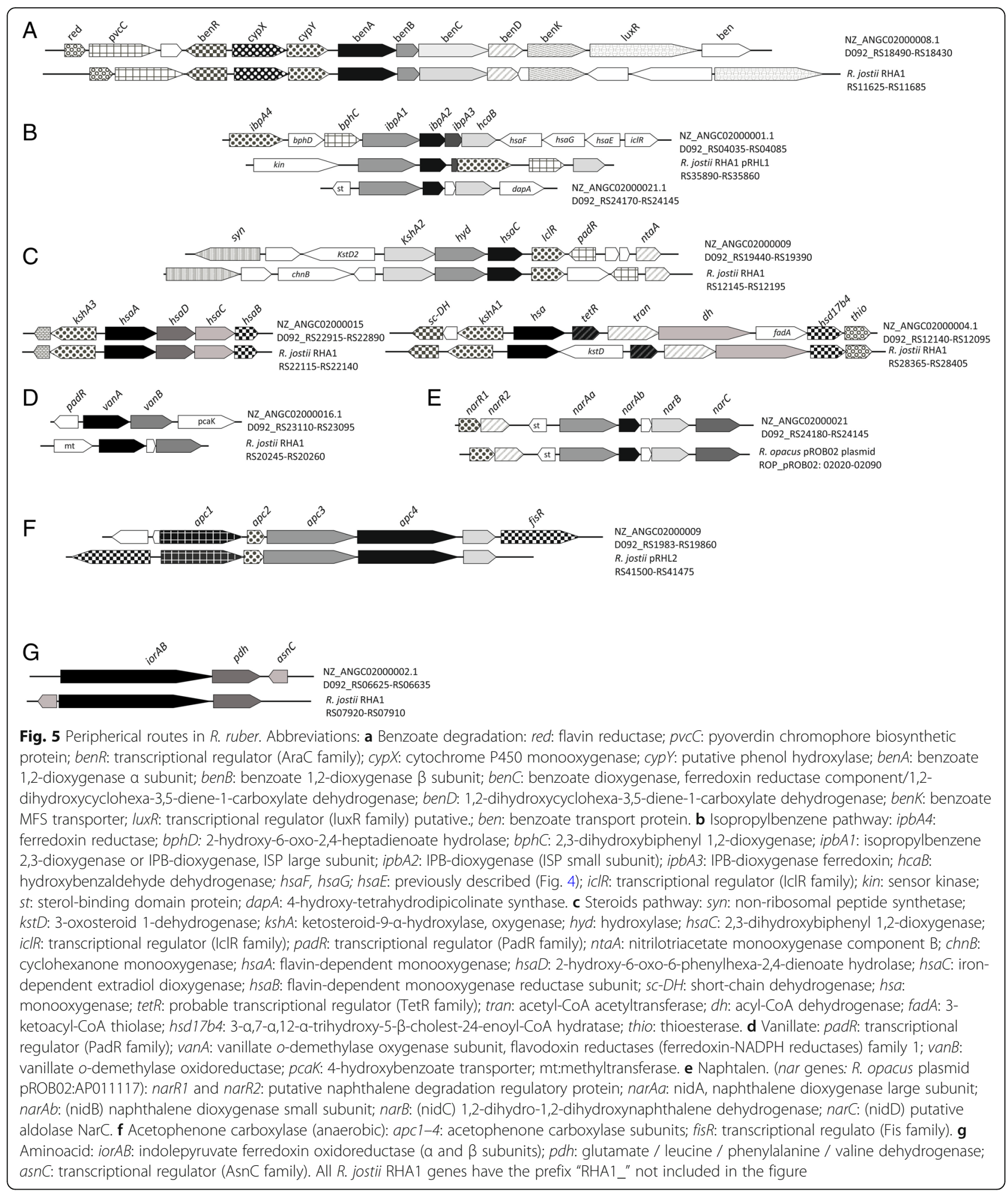

\section{Discussion}

\section{General genome features}

The sequence data employed in this study is the integrated results of two independent sequencing experiments (NCIB database: NZ_ANGC00000000.2). In this work, we present a more comprehensive genomic analysis on this revised sequence, and a comparative analysis with other already described Rhodococcus genome sequences. The published genome size of different Rhodococcus is in the range of 3.9 to $10 \mathrm{Mb}$. This large 


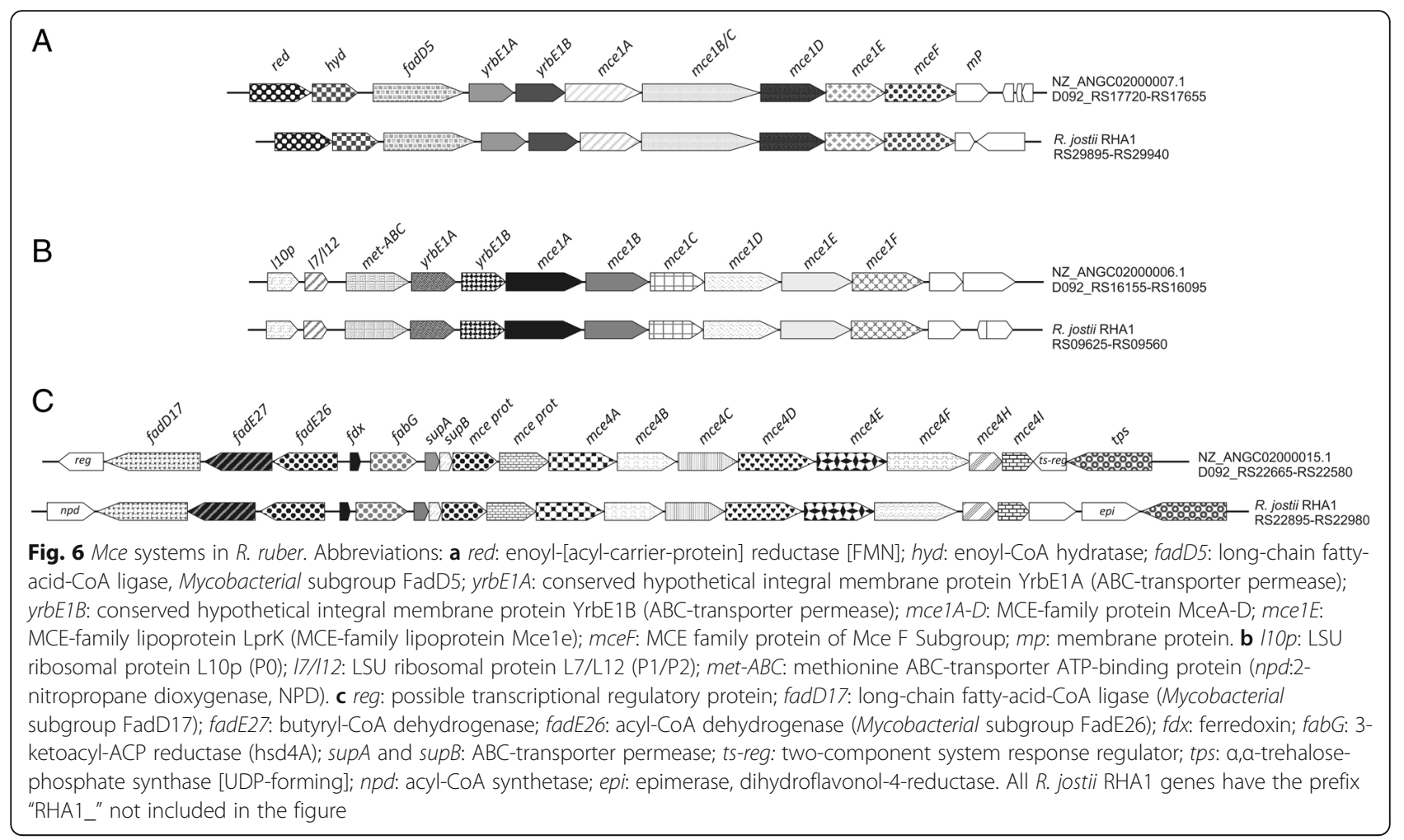

difference in genome size could be related both to the presence of large plasmids and to the extensive genome instability that occurs in several Rhodococcus species [42]. The genome of $R$. ruber Chol- 4 is $5.4 \mathrm{Mb}$ long, a size close to Rhodococcus genome average size (5.69 Mb:

Table 1 Growth of R. ruber Chol-4 wild type on minimum medium with different carbon sources

\begin{tabular}{llll}
\hline Aromatic compounds & Growth & Volatile compounds & Growth \\
\hline catechol & + & 13-butanediol & + \\
cholic acid & + & 2,3-butanediol & + \\
DHEA & + & Isopropanol & + \\
gentisate & + & benzene & - \\
homogentisate & + & ethylbenzene & - \\
L-tryptophan & + & indane & - \\
naphthalene & + & phenylacetic acid & - \\
phenol & + & styrene & - \\
protocathecuate & + & tetralin & - \\
sodium benzoate & + & toluene & - \\
vanillic acid & + & xylene isomers & - \\
2-aminobenzoate & - & & \\
biphenyl & - & & \\
hydroxyquinol & - & & \\
L-tyrosine & - & & \\
phthalate & - & & \\
salicylic acid & - & & \\
\hline
\end{tabular}

https://www.ncbi.nlm.nih.gov/genome/13525) and quite similar to the R. equi ATCC 33707 (5.2 MB), R. pyridinivorans SB3094 (5.6 Mb), $R$. aetherivorans or $R$. fascians A44A (both with $5.9 \mathrm{Mb}$ ) genome.

The analysis of the genomic data suggests that $R$. ruber Chol-4 contains several putative metabolic gene clusters of biotechnological interest, particularly those involved in the catabolism of aromatic compounds (clusters related to the metabolism of benzoate, vanillate, naphtalen, gentisate, etc.) and steroids (for instance, clusters related to cholesterol catabolism) supporting its potential as a model organism for studying aromatic molecules and steroid biodegradation.

Rhodococci are very interesting microorganisms because of their ability to degrade a broad spectrum of aromatic molecules, which are structures very difficult to catabolize and widely distributed in the biosphere. In Rhodococcus strains, the catabolism of aromatic compounds is organized in a modular way that includes peripheral, central and basic pathways (Fig. 3). In the peripheral pathways, aromatic compounds (e.g. biphenyl and phthalate) are converted into specific intermediates (e.g. catechol and phenylacetate) that, in turn, are used in central aromatic pathways to produce a set of common intermediates (e.g. tricarboxylic acid cycle metabolites) that finally are substrates for the basic pathways (Fig. 3) [32]. This kind of organization has been previously named catabolon in other organisms, such as Pseudomonas [43]. 

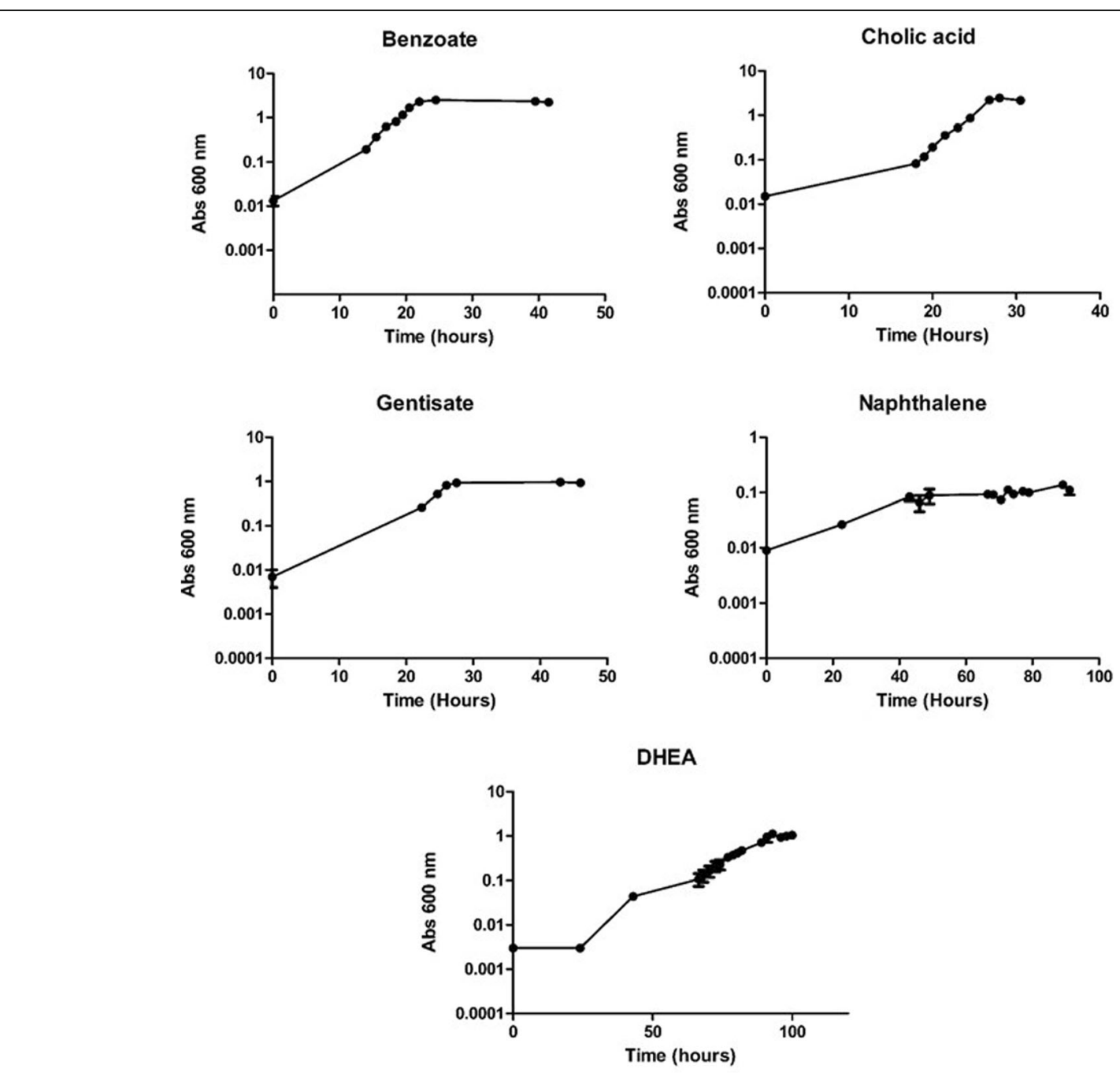

\begin{tabular}{lcc}
\hline Carbon source & Doubling time (hours) & Maximum OD $_{600 \mathrm{~nm}}$ \\
\hline $2.2 \mathrm{mM}$ Cholic acid & $1.8 \pm 0.1$ & $2.6 \pm 0.2$ \\
$10 \mathrm{mM}$ Sodium benzoate & $2.2 \pm 0.2$ & $2.5 \pm 0.1$ \\
$4 \mathrm{mM}$ Gentisate & $2.8 \pm 0.4$ & $1.0 \pm 0.2$ \\
$1 \mathrm{mg} / \mathrm{mL}$ Naphtalen & $15.9 \pm 3.3$ & $0.2 \pm 0.1$ \\
$2 \mathrm{mM}$ DHEA & $7.0 \pm 1.5$ & $1.3 \pm 0.1$ \\
\hline
\end{tabular}

Fig. 7 Growth curves of $R$. ruber WT in minimal medium 457 supplemented with cholic acid, sodium benzoate, gentisate or DHEA. In the case of cholic acid and DHEA $16.5 \mathrm{mM}$ cyclodextrins were present in the medium to increase the solubility of the compounds (no growth when using only cyclodextrins was observed). R. ruber was also grown in minimal medium 457 supplemented with naphthalene in powder (1 mg/mL). Data of 3-4 independent experiments are depicted. The standard error of the mean was calculated by GraphPad Prism 5.0

The central aromatic pathways constitute a catabolic core present in most rhodococci. R. ruber Chol-4 genome contains 7 out of the 8 central aromatic pathways described in both $R$. jostii RHA1 and $R$. opacus B4 [31, 32] (see Fig. 3a) being absent only the phenylacetate pathway. This pathway seems to be characteristic of larger genomes as most of the smallest Rhodococcus genomes ( $R$. equi, $R$. aetherivorans and $R$. pyridinivorans among them) lack also the phenylacetate pathway. However, other pathways such as the genes encoding the gentisate, the homoprotocatechuate and the named VIII pathways found in RHA1 are absent in at least two $R$. erythropolis strains: PR4 and SK121 [32]. Therefore, although most of the aromatic central pathways are conserved within rhodococci, there are metabolic differences 


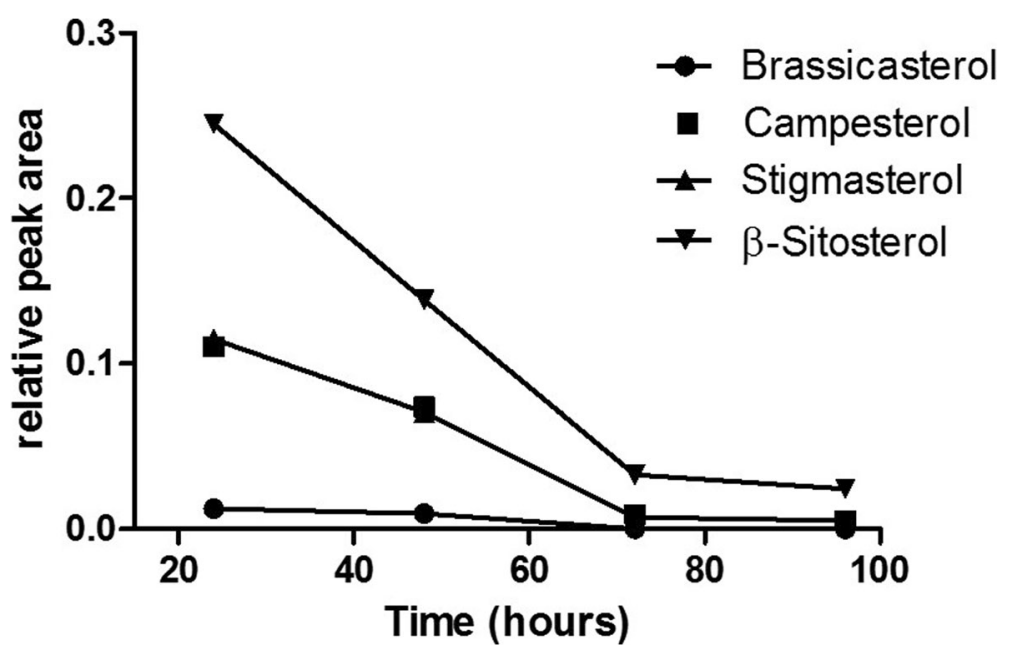

Fig. 8 R. ruber phytosterols comsumption. The strain was inoculated in minimal medium 457 supplemented with a mixture of phytosterols added in powder (brassicasterol, campesterol, stigmasterol and $\beta$-sitosterol). The panel shows the consumption of each compound ( $y$-axis, relative peak area) versus the time since the phytosterol addition to the medium (x-axis). The relative peak area is the ratio between the HPLC peak obtained for each phytosterol and the peak of pregnenolone used as internal control. A representative experiment is shown

among species that could be related to their genome size.

On the other hand, some of the genes detected in the central pathways are redundant in the genome of $R$. ruber Chol-4. Apart from certain enzymatic activities such as KstD and Ksh isoforms previously described in this strain within the steroids catabolism [19, 44, 45],there are also redundant clusters in the $R$. ruber genome such as 3 copies of pcaJ-pcaI involved in the catechol and protocatechuate pathways of the $\beta$-ketoadipate and leucine catabolism that encodes a succinyl-CoA: 3-ketoacid-coenzyme A transferase (EC 2.8.3.5) in NZ_ANGC02000003.1 (D092_RS10690-RS10695), NZ_ANGC02000026.1 (D092_RS24595-RS24600) and NZ_ANGC02000008.1 (D092_RS18665-RS18670) contigs with an amino acid identity of 66-73\% among them and the 2 copies of the hsaEGF cluster (NZ_ANGC02000004.1 contig; Fig. 4 III) with an amino acid identity of $65-78 \%$ belonging to the 2-hydroxypentanodienoate pathway. Gene redundancy in Rhodocci in both catabolic and anabolic pathways is proposed to facilitate high metabolic versatility [4446] or as a mechanism to increase their potential to adapt to new carbon sources [41].

More complex aromatic compounds are partially degraded in the peripheral pathways until they reach one of the intermediates that are substrates of the central aromatic pathways. The number of peripheral pathways present in every Rhodococcus species is variable, probably related with the genomic size or the plasmid content.

In Rhodococcus ruber the pathways related to the catabolism of benzoate, isopropylbenzene, vanillate, napthalen and steroids, among others has been identified. The benzoate clusters ben, cat and $p c a$, are present in the $R$. ruber Chol-4 genome closely located and organized in a similar way to that in $R$. jostii RHA1 (Figs. 4 and 5a) [41]. Rhodococcus jostii strain RHA1 catabolizes benzoate via the cathecol pathway that includes a ring-hydroxylating oxygenase [41]. The cathecol and the protocatechuate branches of the $\beta$-ketoadipate pathway converge at the $\beta$-ketoadipate enol-lactone in this strain.

In $R$. ruber, the genes encoding the isopropylbenzene catabolic pathway are located in NZ_ANGC02000001.1 and NZ_ANGC02000021.1 contigs (Fig. 5b). This aromatic hydrocarbon compound is a constituent in crude oil and refined fuels. The isopropylbenzene gene cluster ipbA1A2A3A4C codes for a reductase (ipbA4), a ferredoxin (ipbA3), a dioxygenase (ipbA1A2) and a 3-isopropylcatechol-2,3-dioxygenase (ipbC) [47].

A gene cluster for vanillate catabolism is found in the R. ruber Chol-4 genome (GenBank: Y11521, Fig. 5d) and it is similar to the gene loci vanA and vanB of Pseudomonas sp. strain HR199. Vanillate is a lignin-derived methoxylated monocyclic aromatic compound whose catabolism proceeds via protocatechuate in Comamonas testosteroni strain BR6020 and in Pseudomonas sp. strain HR199 [48, 49].

The naphtalene-involved nar gene cluster found in $R$. ruber Chol-4 (Fig. 5e) is similar to the cluster present in the plasmid pROB02 of Rhodococcus opacus B4 (NC_012521). In Rhodococcus sp. strain NCIMB 12038 and Rhodococcus opacus R7 the activities proposed to be encoded in the nar cluster are: i) a gentisate 1,2-dioxygenase that converts gentisate into maleylpyruvate; ii) a mycothiol-dependent maleylpyruvate isomerase that catalyzes the isomerization of maleylpyruvate to fumarylpyruvate; and iii) a fumarylpyruvate hydrolase that 


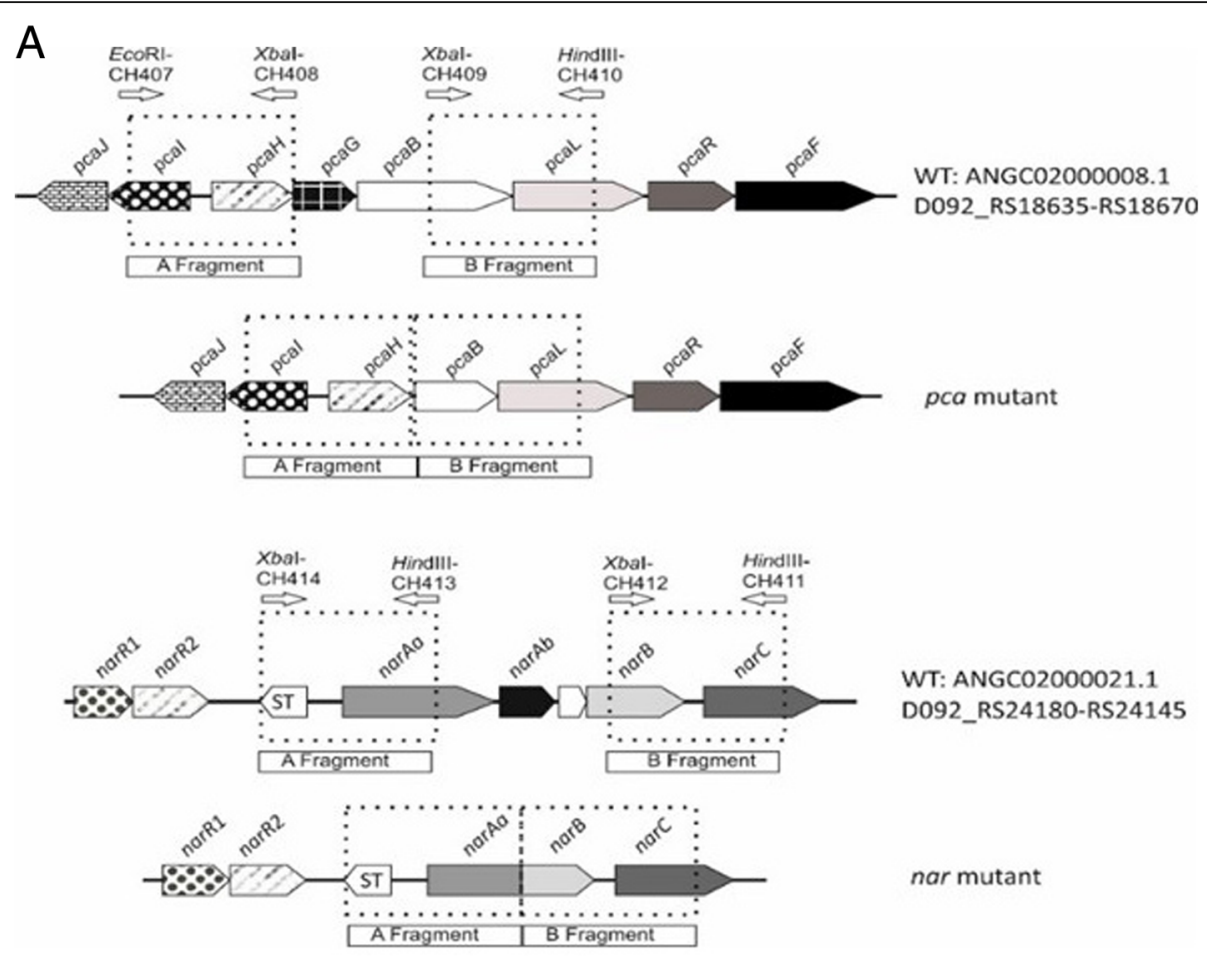

B
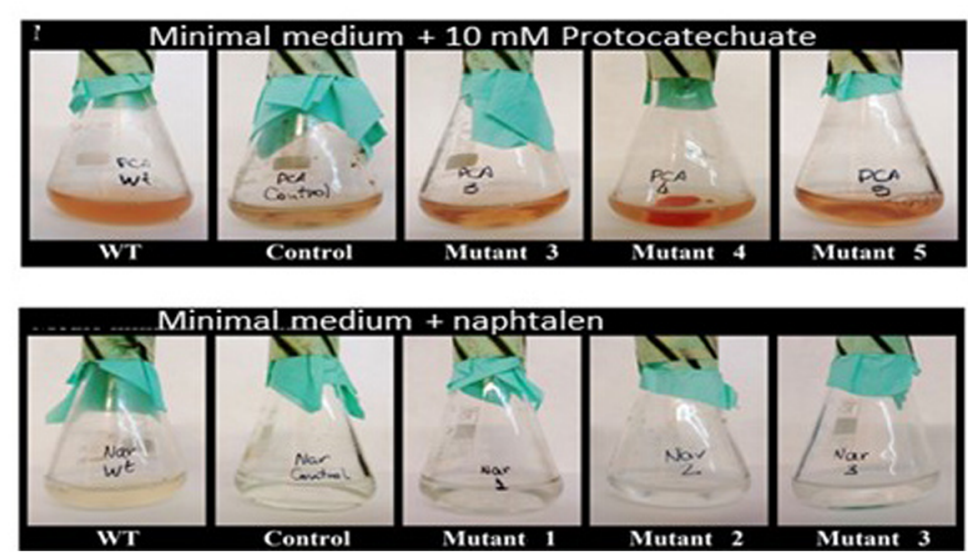

Fig. 9 Rhodococcus ruber mutants. a Scheme of R. ruber deletion pca mutant and nar mutant. b Growth of R. ruber on minimal medium supplemented with $10 \mathrm{mM} \mathrm{PCA}$ or naphthalene in powder $(1 \mathrm{mg} / \mathrm{mL})$, respectively. WT: wild type; pca mutant $(3,4$ and 5$)$ and nar mutant (1-3); control: non-existent growth in the absence of inoculum

Table 2 Growth of $R$. ruber Chol-4 mutants on minimum medium with different carbon sources

\begin{tabular}{llllllllll}
\hline Strain/carbon source & Naph & Benz & Tryp & Cat & Homog & Gen & PCA & Chol & Vanill \\
\hline Wild type & + & + & + & + & + & + & + & + & + \\
nar mutant & - & + & + & + & + & + & + & + & + \\
pca mutant & + & + & + & + & + & + & - & + \\
\hline
\end{tabular}

Naph Naphthalen 7 mM, Benz Benzoate 10 mM, L-Tryp L-tryptophan 5 mM, Cat Catechol 10 mM, Homog Homogentisate 2 mM, Gen Gentisate 4 mM, PCA Protocatechuic acid $10 \mathrm{mM}$, Chol Cholic acid $2.2 \mathrm{mM}$, Vanill Vanillic acid $4 \mathrm{mM}$ 
hydrolyzes fumarylpyruvate to yield fumarate and pyruvate $[50,51]$. The gentisate degradation pathway is shared by both the naphthalene and the 3-hydroxybenzoate catabolism. The nar gene cluster presents a diverse genetic organization with different kind of regulators among Rhodococcus strains [51].Among the genes involved in the last pathway, the dioxygenase thnA1234 cluster could correspond to the isopropylbenzene ipb1234 cluster found in the $R$. ruber genome (Fig. 5b). Therefore, naphthalene could be catabolized in $R$. ruber via either the nar genes or the isopropylbenzene cluster.

Rhodococcus ruber contains many related-steroid clusters (Fig. 5c and Fig. 6). We previously reported other steroid clusters, conferring the ability to grow in different steroids (such as cholesterol, cholestenone, testosterone, 1,4-adrostadien-3,17-dione or 4-7adrostene3,17-dione), and the role of some enzymes such as ketosteroid dehydrogenases, ketosteroid 9- $\alpha$ hydroxylases and cholesterol oxidase [14, 19, 44, 45, 52].

Rhodococci are so broadly known as competent steroid degraders [11] that they could be considered as the steroid-consumer strains by excellence. The cholesterol catabolic pathway has been widely studied, revealing a notable complexity in part due to the existence of alternative pathways and the diversity of the enzymes involved. As steroid intermediates are highly appreciated in the pharmaceutical industries, the steroid catabolic capacity of $R$. ruber strain Chol-4 represents a promising biotechnological platform for the production of steroid drugs.

The steroid degradation genes are generally organized within large gene clusters [53] and this seems also to be the case in $R$. ruber Chol-4. For instance, the cholate catabolic gene cluster found in RHA1 [54] is also present in the $R$. ruber Chol-4 genome (Fig. 5c). Other steroid genes, encompassing the MCE systems, are involved in steroid transport in actinobacteria. Every MCE system is an ATP-binding cassette transporter comprising more than eight distinct proteins. The number of MCE systems could vary among bacteria: from 4 in Mycobacterium tuberculosis H37Rv to 6 in M. smegmatis. The MCE4 system of Rhodococcus jostii RHA1 or Mycobacterium smegmatis has been proved to be an active uptake system that requires ATP to transport steroids such as cholesterol, 5- $\alpha$-cholestanol, 5- $\alpha$-cholestanone or $\beta$-sitosterol $[38,39]$. The other mce operons could be involved in the cell envelope structure maintenance [39]. We found three MCE systems in $R$. ruber Chol-4 (Fig. 6). One of them, lying in NZ_ANGC02000015.1 contig, exhibited the higher similarity with the mce4 system of RHA1. Consequently, we propose that this MCE system would be related to steroid transport.
On the other hand, although $R$. ruber can grow on cholate [44], no ORFs similar to the RHA1 cholate transport system, i.e. the $\mathrm{ABC}$-transporter $\operatorname{CamABCD}$ ro04888 to ro04885 and CamM ro05792 [55] were detected. This suggest that cholate transport systems could differ within Rhodoccus species.

\section{Experimental analysis of $R$. ruber catabolic capabilities}

The growth results were in accordance with the theoretical data from the identification of gene clusters within the genome of Rhodococcus ruber Chol-4. For instance, the failure to grow on volatile compounds (benzene, toluene, etc.) could be explained by the absence of specific clusters involved in the catabolism of these compounds.

However, there were some interesting exceptions: $R$, ruber Chol-4 did not grow on hydroxyquinol despite the fact that the pathway VI genes are present in its genome (see Fig. 3). It neither grew on salicylate, although up to two putative salicylate hydroxylases (EC 1.14.13.1) were found in its genome (D092_RS04015 in NZ_ANGC02000001.1 contig and D092_RS16585 NZ_ANGC02000006.1 contig).

Some interesting observations were revealed by the in vitro growth experiments. $R$. ruber grew on benzoate, catechol and protocatechuic acid. Therefore, the catabolism of benzoate could take place via the cathecol pathway through a ring-hydroxylating oxygenase as it has been proposed for RHA1 [41]. On the other hand, $R$. ruber grew on naphthalene as sole organic substrate (Fig. 7 and Table 1). As stated before, two different pathways for naphthalene catabolism have been described in Rhodococci to date, one relying on the nar cluster and the other relying on the isopropylbenzene cluster (ipb) $[51,56]$, both converging on salicylate which is subsequently hydroxylated to gentisate. Thus, the fact that $R$. ruber grew in naphthalene and gentisate, but not in salicylate, was perplexing, and suggested that the intake of this compound might be hampered or, a more provoking hypothesis, that this strain catabolizes naphthalene through an alternative pathway that would not involve salicylate as intermediate. More studies should be taken to elucidate this apparent paradox.

\section{Mutant construction}

In order to check the functionality of several of the pathways putatively identified in $R$. ruber two groups of genes were deleted. On one hand, protocatechuate 3,4-dioxygenase $\alpha$ chain $(p c a G)$ and the 3-carboxy-cis,cis-muconate cycloisomerase $(p c a B)$ genes of the cluster related to the protocatechuic acid pathway were deleted (Figs. 9 and 4I). The $R$. ruber Chol-4 pca mutants were not able to grow on protocatechuate (Fig. 9) showing that the pca gene cluster is directly involved in the metabolism of protocatechuate. The growth on vanillate also resulted to be dependent on the $p c a$ cluster in this strain (Fig. 3). A 
RHA1 pca mutant also failed to grow on vanillate as the sole organic substrate suggesting that this substrate is degraded via the $\beta$-ketoadipate pathway [57]. On the other hand, deletion of the naphthalene dioxygenase nar genes led to the loss of growth on naphthalene (Figs. 9 and 5e). Therefore, the nar gene cluster is responsible of the naphthalene catabolism in $R$. ruber Chol-4, while the ipb gene cluster is not involved in that degradation.

\section{Conclusions}

In summary, the analysis of the Rhodococcus ruber strain Chol-4 genome substantiated its relevance as a model organism for studying steroid and aromatic compounds biodegradation. The agreement between gene clusters found in the genome and the growth results of $R$. ruber has been established. $R$. ruber is able to grow in minimal medium with steroids (e.g. cholesterol, phytosterols, DHEA), bile acids (cholic acid) or several aromatic compounds (e.g. benzoate, naphthalene, gentisate) as the only source of carbon and energy. Deeper studies on Chol-4 degradation capabilities based on the construction of some mutants revealed that the nar gene cluster is indeed involved in the naphthalene catabolism in $R$. ruber, while the pca gene cluster is responsible of the metabolism of both protocatechuate and vanillate.

Our results confirm and reinforce the biotechnological interest of $R$. ruber strain Chol-4 due to its metabolic potential that opens a great variety of applications as, for instance, its use in the bacterial transformation of steroids to produce pharmaceutically active steroid drugs. Further studies will be focused in exploring $R$. ruber Chol-4 novel potential biotechnological applications.

\section{Additional files}

Additional file 1: Table S1. Bacterial strains and plasmids used in this work. (DOCX $17 \mathrm{~kb}$ )

Additional file 2: Growth in gas phase via saturated atmosphere. (JPG $88 \mathrm{~kb}$ )

Additional file 3: Table S2. Primers used in this work. (DOCX $13 \mathrm{~kb}$ )

Additional file 4: Figure S1. Sequence length vs GC content of the 129 scaffolds obtained in the initial assembly of R. ruber Chol-4 genome. (DOCX $428 \mathrm{~kb}$ )

Additional file 5: Quast genome assembly evaluation. (PDF $30 \mathrm{~kb}$ )

Additional file 6: Table S3. Anticodons encoded in the R. ruber Chol-4 genome. (DOCX $20 \mathrm{~kb}$ )

Additional file 7: Table S4. List of mobile elements found in the $R$. ruber Chol-4 genome. (DOCX $25 \mathrm{~kb}$ )

Additional file 8: Table S5. List of recombinases identified in the $R$. ruber Chol-4 genome. (DOCX $19 \mathrm{~kb}$ )

Additional file 9: Table S6. List of restriction modification systems identified in the R. ruber Chol-4 genome. (DOCX $18 \mathrm{~kb}$ )

\section{Abbreviations}

CRISPR: Clustered regularly interspaced short palindromic repeats; DHEA: Dehydroepiandrosterone; HPLC: High performance liquid chromatography; LB: Luria Bertani; MCE: Mammalian cell entry system; NGS: Next Generation Sequencing; ORF: Open reading frame;

PCR: Polymerase chain reaction

\section{Acknowledgments}

We are very grateful to Jose Luis Garcia (CIB) for sharing his broad knowledge and support and to Laura Fernández de las Heras for her help at the initial stages of this work.

\section{Funding}

This work has been supported by projects RTC-2014-2249-1 and BIO201239695-CO2-01 from MINECO, Spain. The funders had no role in study design, data collection and analysis, decision to publish, or preparation of the manuscript.

\section{Availability of data and materials}

The authors confirm that all data underlying the findings are fully available without restriction. The whole Genome Shotgun projects are linked to BioProjects PRJNA224116 and PRJNA176883. The Whole Genome Shotgun projects have been deposited at DDBJ/EMBL/GenBank under the accession number NZ_ANGC00000000. The version described in this paper is NZ ANGC00000000.2.

Authors' contributions

$J M N, J P$ and $G G$ conceived and designed the experiments. GG and MCL made the mutants. GG, MCL and JMN made the growth experiments. $S A$, GG, JMN and JP analyzed the genomic data. SA contributed with analysis tools to this work. GG, SA, JMN and JP contributed to the writing of the manuscript. All authors read and approved the manuscript.

Ethics approval and consent to participate

Not applicable.

Consent for publication

Not applicable.

Competing interests

The authors have declared that they have no competing interests exist.

\section{Publisher's Note}

Springer Nature remains neutral with regard to jurisdictional claims in published maps and institutional affiliations.

\section{Author details}

'Departamento de Bioquímica y Biología Molecular, Facultad de Ciencias Biológicas, Universidad Complutense de Madrid, Madrid, Spain. ${ }^{2}$ Program of Predictive and Personalized Medicine of Cancer (PMPPC), Germans Trias i Pujol Research Institute (IGTP), Carretera de Can Ruti S/N 08916 Badalona, Barcelona, Spain.

Received: 14 June 2018 Accepted: 8 April 2019

Published online: 02 May 2019

\section{References}

1. Finnerty WR. The biology and genetics of the genus Rhodococcus. Annu Rev Microbiol. 1992;46:193-218.

2. Sutcliffe IC, Brown AK, Dover LG. In: Alvarez HM, editor. The Rhodococcal cell envelope: composition, organisation and biosynthesis. Berlin Heidelberg: Springer: 2010

3. Pachebat JA, van Keulen G, Whitten MM, Girdwood S, Del Sol R, Dyson PJ, Facey PD. Draft genome sequence of Rhodococcus rhodnii strain LMG5362, a symbiont of Rhodnius prolixus (Hemiptera, Reduviidae, Triatominae), the principle vector of Trypanosoma cruzi. Genome Announc. 2013;1(3):e0032913. https://doi.org/10.1128/genomeA.00329-13.

4. Kuyukina MS, Ivshina IB. In: Alvarez HM, editor. Application of Rhodococcus in bioremediation of contaminated environments. Berlin Heidelberg: Springer-Verlag; 2010.

5. Alvarez HM. Biology of Rhodococcus, vol. 16. Berlin Heidelberg: SpringerVerlag; 2010.

6. Francis I, De Keyser A, De Backer P, Simon-Mateo C, Kalkus J, Pertry I, Ardiles-Diaz W, De Rycke R, Vandeputte OM, El Jaziri M, et al. pFiD188, the 
linear virulence plasmid of Rhodococcus fascians D188. Mol Plant-Microbe Interact. 2012;25:637-47.

7. Shimizu S, Kobayashi H, Masai E, Fukuda M. Characterization of the 450-kb linear plasmid in a polychlorinated biphenyl degrader, Rhodococcus sp. strain RHA1. Appl Environ Microbiol. 2001;67:2021-8.

8. Kulakova AN, Stafford TM, Larkin MJ, Kulakov LA. Plasmid pRTL1 controlling 1-chloroalkane degradation by Rhodococcus rhodochrous NCIMB13064. Plasmid. 1995;33:208-17.

9. Imabuchi N, Sunairi M, Urai M, Itoh C, Anzai H, Nakajima M, Harayama S. Extracellular polysaccharides of Rhodococcus rhodochrous S-2 stimulate the degradation of aromatic components in crude oil by indigenous marine bacteria. Appl Environ Microbiol. 2002;68:2337-43.

10. Martínková L, Uhnakova B, Patek M, Nesvera J, Kren V. Biodegradation potential of the genus Rhodococcus. Environ Int. 2009;35:162-77.

11. Yam KC, Okamoto S. Adventures in Rhodococcus - from steroids to explosives. Can J Microbiol. 2011;57:155-68.

12. Kuyukina MS, Ivshina IB. Rhodococcus biosurfactants: biosynthesis, properties, and potential applications. Berlin Heidelberg: Springer-Verlag; 2010.

13. García JL, Uhía I, Galan B. Catabolism and biotechnological applications of cholesterol degrading bacteria. Microb Biotechnol. 2012;5:679-99.

14. Fernández de Las Heras L, García Fernández E, Navarro Llorens JM, Perera J, Drzyzga O. Morphological, physiological, and molecular characterization of a newly isolated steroid-degrading actinomycete, identified as Rhodococcus ruber strain Chol-4. Curr Microbiol. 2009;59:548-53.

15. Fernández de las Heras L, Alonso S, de la Vega de Leon A, Xavier D, Perera J, Navarro Llorens JM. Draft genome sequence of the steroid degrader Rhodococcus ruber strain Chol-4. Genome Announc. 2013;1(3):e00215-13. https://doi.org/10.1128/genomeA.00215-13.

16. Sambrook J, Fritsch EF, Maniatis T. Molecular cloning: a laboratory manual. New York: Cold Spring Harbor Laboratory Press; 1989.

17. Klein U, Gimpl G, Fahrenholz F. Alteration of the myometrial plasma membrane cholesterol content with b-cyclodextrin modulates the binding affinity of the oxytocin receptor. Biochemistry. 1995;34:13784-93.

18. Fernández de las Heras L, Mascaraque V, García Fernandez E, Navarro-Llorens JM, Perera J, Drzyzga O. ChoG is the main inducible extracellular cholesterol oxidase of Rhodococcus sp. strain CECT3014. Microbiol Res. 2011;166:403-18.

19. Fernández de las Heras L, van der Geize R, Drzyzga O, Perera J, Maria Navarro Llorens J. Molecular characterization of three 3-ketosteroid-Delta (1)-dehydrogenase isoenzymes of Rhodococcus ruber strain Chol-4. J Steroid Biochem Mol Biol. 2012;132:271-81.

20. Bankevich A, Nurk S, Antipov D, Gurevich AA, Dvorkin M, Kulikov AS, Lesin VM, Nikolenko SI, Pham S, Prijbelski AD, et al. SPAdes: a new genome assembly algorithm and its applications to single-cell sequencing. J Comput Biol. 2012;19:455-77.

21. Gurevich A, Saveliev V, Vyahhi N, Tesler G. QUAST: quality assessment tool for genome assemblies. Bioinformatics. 2013;29:1072-5.

22. van der Geize R, Hessels Gl, van Gerwen R, van der Meijden P, Dijkhuizen L. Unmarked gene deletion mutagenesis of kstD, encoding 3-ketosteroid Delta1-dehydrogenase, in Rhodococcus erythropolis SQ1 using sacB as counter-selectable marker. FEMS Microbiol Lett. 2001;205:197-202.

23. Schafer A, Tauch A, Jager W, Kalinowski J, Thierbach G, Puhler A. Small mobilizable multi-purpose cloning vectors derived from the Escherichia coli plasmids pK18 and pK19: selection of defined deletions in the chromosome of Corynebacterium glutamicum. Gene. 1994;145:69-73.

24. Krzywinski M, Schein J, Birol I, Connors J, Gascoyne R, Horsman D, Jones SJ, Marra MA. Circos: an information aesthetic for comparative genomics. Genome Res. 2009;19:1639-45.

25. Aziz RK, Bartels D, Best AA, DeJongh M, Disz T, Edwards RA, Formsma K, Gerdes S, Glass EM, Kubal M, et al. The RAST server: rapid annotations using subsystems technology. BMC Genomics. 2008;9:75.

26. Kulakov LA, Poelarends GJ, Janssen DB, Larkin MJ. Characterization of IS2112, a new insertion sequence from Rhodococcus, and its relationship with mobile elements belonging to the IS110 family. Microbiology. 1999;145:561-8.

27. Denome SA, Young KD. Identification and activity of two insertion sequence elements in Rhodococcus sp. strain IGTS8. Gene. 1995;161:33-8.

28. Botelho A, Canto A, Leao C, Cunha MV. Clustered regularly interspaced short palindromic repeats (CRISPRs) analysis of members of the Mycobacterium tuberculosis complex. Methods Mol Biol. 2015;1247:373-89.

29. Bode NJ, Darwin KH. The Pup-Proteasome System of Mycobacteria. Microbiol Spectr. 2014; 2(5). https://doi.org/10.1128/microbiolspec.MGM20008-2013.
30. Voges $D, Z$ wickl P, Baumeister W. The 265 proteasome: a molecular machine designed for controlled proteolysis. Annu Rev Biochem. 1999;68: 1015-68.

31. McLeod MP, Warren RL, Hsiao WW, Araki N, Myhre M, Fernandes C, Miyazawa D, Wong W, Lillquist AL, Wang D, et al. The complete genome of Rhodococcus sp. RHA1 provides insights into a catabolic powerhouse. Proc Natl Acad Sci U S A. 2006;103:15582-7.

32. Yam KC, van der Geize R, Eltis LD. In: Alvarez HM, editor. Catabolism of aromatic compounds and steroids by Rhodococcus. Berlin Heidelberg: Springer-Verlag; 2010.

33. Navarro Llorens JM, Patrauchan MA, Stewart GR, Davies JE, Eltis LD, Mohn WW. Phenylacetate catabolism in Rhodococcus sp. strain RHA1: a central pathway for degradation of aromatic compounds. J Bacteriol. 2005;187: 4497-504.

34. van der Geize R, Yam K, Heuser T, Wilbrink MH, Hara H, Anderton MC, Sim E, Dijkhuizen L, Davies JE, Mohn WW, et al. A gene cluster encoding cholesterol catabolism in a soil actinomycete provides insight into Mycobacterium tuberculosis survival in macrophages. Proc Natl Acad Sci U S A. 2007;104:1947-52

35. Suemori A, Nakajima K, Kurane R, Nakamura Y. O-, m- and phydroxybenzoate degradative pathways in Rhodococcus erythropolis. FEMS Microbiol Lett. 1995;125:31-5.

36. Arias-Barrau E, Olivera ER, Luengo JM, Fernandez C, Galan B, Garcia JL, Diaz E, Minambres B. The homogentisate pathway: a central catabolic pathway involved in the degradation of L-phenylalanine, L-tyrosine, and 3hydroxyphenylacetate in Pseudomonas putida. J Bacteriol. 2004;186:5062-77.

37. Travkin VM, Solyanikova IP, Golovleva LA. Hydroxyquinol pathway for microbial degradation of halogenated aromatic compounds. J Environ Sci Health B. 2006;41:1361-82.

38. Mohn WW, van der Geize R, Stewart GR, Okamoto S, Liu J, Dijkhuizen L, Eltis LD. The actinobacterial mce4 locus encodes a steroid transporter. J Biol Chem. 2008;283:35368-74

39. Klepp LI, Forrellad MA, Osella AV, Blanco FC, Stella EJ, Bianco MV, Santangelo MD, Sassetti C, Jackson M, Cataldi AA, et al. Impact of the deletion of the six mce operons in Mycobacterium smegmatis. Microbes Infect. 2012:14:590-9.

40. Goncalves ER, Hara H, Miyazawa D, Davies JE, Eltis LD, Mohn WW. Transcriptomic assessment of isozymes in the biphenyl pathway of Rhodococcus sp. strain RHA1. Appl Environ Microbiol. 2006;72:6183-93.

41. Patrauchan MA, Florizone C, Dosanjh M, Mohn WW, Davies J, Eltis LD. Catabolism of benzoate and phthalate in Rhodococcus sp. strain RHA1: redundancies and convergence. J Bacteriol. 2005;187:4050-63.

42. Larkin MJ, Kulakov LA, Allen CCR. In: Alvarez HM, editor. Genomes and Plasmids in Rhodococcus. Berlin Heidelberg: Springer-Verlag; 2010.

43. Luengo JM, Garcia JL, Olivera ER. The phenylacetyl-CoA catabolon: a complex catabolic unit with broad biotechnological applications. Mol Microbiol. 2001;39:1434-42.

44. Guevara G, Fernandez de Las Heras L, Perera J, Navarro Llorens JM. Functional differentiation of 3-ketosteroid Delta (1)-dehydrogenase isozymes in Rhodococcus ruber strain Chol-4. Microb Cell Factories. 2017;16:42.

45. Guevara G, Heras LFL, Perera J, Llorens JMN. Functional characterization of 3-ketosteroid 9alpha-hydroxylases in Rhodococcus ruber strain chol-4. J Steroid Biochem Mol Biol. 2017;172:176-87.

46. Gröning JA, Eulberg D, Tischler D, Kaschabek SR, Schlomann M. Gene redundancy of two-component (chloro)phenol hydroxylases in Rhodococcus opacus 1CP. FEMS Microbiol Lett. 2014;361:68-75.

47. Kesseler M, Dabbs ER, Averhoff B, Gottschalk G. Studies on the isopropylbenzene 2,3-dioxygenase and the 3-isopropylcatechol 2,3dioxygenase genes encoded by the linear plasmid of Rhodococcus erythropolis BD2. Microbiology. 1996;142(Pt 11):3241-51.

48. Providenti MA, O'Brien JM, Ruff J, Cook AM, Lambert IB. Metabolism of isovanillate, vanillate, and veratrate by Comamonas testosteroni strain BR6020. J Bacteriol. 2006;188:3862-9.

49. Priefert H, Rabenhorst J, Steinbuchel A. Molecular characterization of genes of Pseudomonas sp. strain HR199 involved in bioconversion of vanillin to protocatechuate. J Bacteriol. 1997;179:2595-607.

50. Liu T, Xu Y, Liu H, Luo S, Yin YJ, Liu SJ, Zhou NY. Functional characterization of a gene cluster involved in gentisate catabolism in Rhodococcus sp. strain NCIMB 12038. Appl Microbiol Biotechnol. 2011; 90:671-8. 
51. Di Gennaro P, Terreni P, Masi G, Botti S, De Ferra F, Bestetti G. Identification and characterization of genes involved in naphthalene degradation in Rhodococcus opacus R7. Appl Microbiol Biotechnol. 2010;87:297-308.

52. Fernández de las Heras L, Perera J, Navarro Llorens JM. Cholesterol to cholestenone oxidation by ChoG, the main extracellular cholesterol oxidase of Rhodococcus ruber strain Chol-4. J Steroid Biochem Mol Biol. 2014;139:33-44.

53. Bergstrand LH, Cardenas E, Holert J, Van Hamme JD, Mohn WW. Delineation of Steroid-Degrading Microorganisms through Comparative Genomic Analysis. MBio. 2016;7(2):e00166. https://doi.org/10.1128/mBio.00166-16.

54. Mohn WW, Wilbrink MH, Casabon I, Stewart GR, Liu J, van der Geize R, Eltis LD. Gene cluster encoding cholate catabolism in Rhodococcus spp. J Bacteriol. 2012;194:6712-9.

55. Swain K, Casabon I, Eltis LD, Mohn WW. Two transporters essential for reassimilation of novel cholate metabolites by Rhodococcus jostii RHA1. J Bacteriol. 2012;194:6720-7.

56. Tomas-Gallardo L, Gomez-Alvarez H, Santero E, Floriano B. Combination of degradation pathways for naphthalene utilization in Rhodococcus sp. strain TFB. Microb Biotechnol. 2014;7:100-13.

57. Chen HP, Chow M, Liu CC, Lau A, Liu J, Eltis LD. Vanillin catabolism in Rhodococcus jostii RHA1. Appl Environ Microbiol. 2012;78:586-8.

Ready to submit your research? Choose BMC and benefit from:

- fast, convenient online submission

- thorough peer review by experienced researchers in your field

- rapid publication on acceptance

- support for research data, including large and complex data types

- gold Open Access which fosters wider collaboration and increased citations

- maximum visibility for your research: over $100 \mathrm{M}$ website views per year

At $\mathrm{BMC}$, research is always in progress.

Learn more biomedcentral.com/submissions 